\title{
O MAR ENGOLIU A PRAIA NA AMAZÔNIA: ORIGEM DA COMUNIDADE DO CASTELO NARRADA PELOS MORADORES LOCAIS, BRAGANÇA, PARÁ.
}

\author{
Maria Adriana Leite ${ }^{1}$ \\ Divino Bruno Cunha ${ }^{2}$ \\ Luis Junior Costa Saraiva ${ }^{3}$
}

\begin{abstract}
RESUMO
O uso de fotografias e narrativas de sujeitos é amplamente utilizado como auxílio à compreensão de possibilidades de registros das variadas faces da vida social. O presente estudo tem como objetivo demonstrar a relevância das fotografias para os estudos no campo da memória social, em acervo da comunidade do Castelo, Bragança-PA, através de narrativas e representação. A partir disso, foi possível propormos como ocorreu o processo de sua "fundação" e povoamento da comunidade, fazendo a relação com a pesca. As narrativas revelam a existência de um patrimônio simbólico e a presença de uma memória (legado de gerações) movendo os grupos familiares.
\end{abstract}

Palavras-chave: Fotografia. Memória. Comunidade do Castelo.

\begin{abstract}
Photographic records and subject narratives is widely used to understand the wide possibilities of recording the various faces of social life. The present study aimed to demonstrate the relevance of the photographs for studies in the field of social memory, in a collection of the Castle Community/Bragança-PA, through narrative and representation. From this it was possible to propose how the process of its "foundation" and settlement in the community occurred, making the relationship with fishing. The narratives reveal the existence of a symbolic patrimony and the presence of a memory (legacy of generations) moving the family groups.
\end{abstract}

Keywords: Photography. Memory. Castle Community.

\section{INTRODUÇÃO}

A maioria das comunidades pesqueiras e ribeirinhas da Amazônia herdou saberes e valores culturais a partir de suas origens indígenas, caboclas, portuguesas e africanas, o que contribuiu para o cenário cultural diferenciado dessa região, não sendo, assim, uma região de fácil definição (LIRA e CHAVES, 2015). A cidade de Bragança é um exemplo de tal formação, situada no nordeste do Estado do Pará com cerca de 115 mil habitantes (IBGE, 2010) e com um grande potencial para atividades pesqueiras, abriga diversas comunidades

\footnotetext{
${ }^{1}$ Mestre em Linguagens e Saberes na Amazônia, pela Universidade federal do Pará.

${ }^{2}$ Doutor em Biologia ambiental pela UFPA e docente na Universidade Estadual da Região Tocantina do Maranhão.

${ }^{3}$ Doutor em Antropologia. Professor Adjunto FACED/UFPA, Campus de Bragança. Membro do grupo de Pesquisa e Estudos Socioambientais Costeiros (ESAC). Professor da Pós-graduação em Linguagens e Saberes na Amazônia/UFPA. E-Mail: luisjsaraiva@ gmail.com
} 
distintas. Segundo Garvão, Bahia e Tourinho (2015) Bragança é banhada pelo Rio Caeté, cujo estuário situa-se próximo da porção central do litoral do Salgado, na microrregião Bragantina, fazendo parte da planície costeira bragantina do estado do Pará.

De acordo com Lira e Chaves (2015) a água é um fator preponderante nesses espaços, sendo a vida cotidiana das populações dessa região marcada por uma paisagem voltada para o movimento das marés e a relação desses povos com a natureza é um dos principais fatores responsáveis pela organização de espaço/tempo do trabalho. No caso dos pescadores, o Rio Caeté-Taperaçú, localizado na península bragantina, é um elemento preponderante ao exercício das atividades pesqueiras, de caráter comercial e de subsistência. Consequentemente o rio passa a ditar o tempo da pesca e o espaço de mediação de cultura entre os povos.

Os saberes presentes nas comunidades não se limitam apenas à atividade pesqueira, principalmente no que se refere às comunidades que possuem difícil acesso à parte urbanizada da cidade, o que gera mecanismos que os possibilitam a aprendizagem de outros saberes para sobreviver apenas com os recursos disponíveis naquele espaço (DIEGUES, 1999). A presente comunidade do Castelo passou inicialmente por esse processo de formação. Os moradores mais "antigos" viviam em uma praia localizada no litoral bragantino, chamada Picanço ${ }^{4}$, mas devido uma grande enchente, os moradores tiveram que se deslocar para outro lugar e consigo levaram conhecimentos oriundos das suas famílias, para continuação da vida nesse novo espaço, recomeçando. Porém, sem esquecer os saberes anteriores.

Ao estudarmos o contexto histórico de uma comunidade, precisamos saber como ocorreu o seu processo de fundação e formação dos povos que ali habitam. Um dos recursos importantes para tal análise é o uso das fotografias que podem proporcionar uma reflexão e contribuir para o entendimento no processo de organização dos grupos. Elas nos auxiliam nas diferentes formas de sentir e medir suas paisagens, como podemos observar abaixo:

\footnotetext{
Produto de uma série de escolhas, a fotografia é um ato cultural que reflete a maneira de pensar e ver o mundo do seu autor (Novaes, 1998:117) tanto quanto os objetivos que motivaram a sua produção. "Você fotografa o que vê, e vê o que é", já sentenciou o fotógrafo José Medeiros, um dos mais reconhecidos olhares sobre a realidade brasileira da segunda metade do século XX. (GURAN, 2005, p. 2)
}

Como exercício de reconhecimento e entendimento do povoamento da comunidade do Castelo, Bragança-PA, nesse artigo propomos descrever como se deu a formação dessa

\footnotetext{
${ }^{4}$ Extinta ilha localizada próxima à Vila do Castelo, inundada por uma alta maré de março na década de 80. Localizada próxima à ilha de Canelas, na península bragantina.
} 
comunidade e fazer uma viagem pelas narrativas fotográficas de moradores, os quais guardam, em suas memórias, um acervo valiosíssimo de narrativas que auxiliam na compreensão da construção social e estrutural da comunidade do Castelo. A metodologia utilizada para a realização deste trabalho baseia-se nas histórias contadas através de entrevistas e roda de conversa com moradores que já vivem há bastante tempo na comunidade, atentando aos que estiveram presentes no episódio da inundação e na posterior mudança da praia do Picanço para a comunidade do Castelo, observando o processo de formação dessa vila, por meio das memórias dos moradores, com suas vivências e a história de vida em comunidade.

\section{HISTÓRIA CONTADA PELOS MORADORES DA COMUNIDADE: NO PASSADO.}

Segundo relatos de alguns moradores, a Vila do Castelo surgiu a partir da necessidade de migração de um grupo de 15 famílias, que moravam em uma pequena praia chamada de Praia do Picanço. No final da década de 70, a praia estava sendo inundada pelas fortes águas de março ${ }^{5}$ e os moradores se viram obrigados a deixar seus lares, devido ao nível do mar subir rapidamente.

Feitosa (2012) em seu estudo realizou uma entrevista com os antigos moradores da Praia do Picanço, dentre as quais, destaca-se a transcrição oral de uma senhora chamada Adelina, moradora da comunidade, que integrava uma das 15 famílias oriundas da Praia de Picanço. Seus relatos refletem bem o que as famílias passaram no tal episódio.

\footnotetext{
Quando chegou no ano de 79, a cheia foi grande. No inverno, mês de março, uma cheia muito grande que lavou a praia toda, lavou tudo. Esse aqui pegava a canoa e amarrava no esteio da casa. A água quando vinha quebrava aqueles banzeiros na casa e passava por dentro. (O esposo aponta a altura do peito por onde a água dava dentro de casa). As coisas tudo trepada. Em cima do girau. Era pato, era galinha. Era tudo atrepado. Era três águas, três marés que passou, na mesma semana. É água de lua. Vem a enchente, vaza, vem a enchente, vaza, vem a enchente, vaza. E foi um desespero para gente, para todos que moravam lá. Aí esbandalhou a praia. Não teve como. Não se tinha água para beber. (apud FEITOSA, 2012. p.11)
}

O relato da Sra. Adelina, apresentada pelo autor, nos apresenta a importância da memória para a construção histórica de fatos sociais que não poderiam ser registrados por outros mecanismos. Faz-nos refletir, ainda, no conjunto de saberes que as comunidades

\footnotetext{
${ }^{5}$ Águas de março, para a região aqui em pauta, diz respeito ao período chuvoso, quando ocorre as marés mais altas.
} 
pesqueiras detêm em relação as águas, principalmente, a forma como se comportam as marés e as influências que estas sofrem com os ciclos lunares.

O nome Castelo, de acordo com o pescador Manoel, conhecido como Maroca, 74 anos, começou de uma brincadeira, pois ao chegarem no novo espaço de moradia, para construir suas habitações se depararam com muitos castelos de formigas. Com isso, ironizavam dizendo que agora sim iriam viver em um verdadeiro Castelo. Embora não tivessem mais suas casas iniciais, os pescadores possuíam água e suas famílias estavam salvas da enchente, como Maroca ${ }^{6}$ afirma: "daí o nome foi pegando e nós batizamos como Vila do Castelo, hoje sendo chamada por Comunidade do Castelo".

Atualmente, a comunidade do Castelo, de acordo com dados das agentes de saúde, é formada por 213 famílias (censo 2012) com aproximadamente 1500 moradores. Possui uma escola municipal, a qual leva o nome da primeira professora que foi atuar na comunidade (Escola Maria Augusta), uma Igreja (Católica) e um centro comunitário, onde ocorre boa parte dos eventos da localidade, envolvendo reuniões, encontros, festas comemorativas e atividades da escola. Além disso, ultimamente a comunidade faz parte da Associação dos Extrativistas da Reserva Extrativista Marinha Caeté-Taperaçu (ASSUREMACATA).

A moradora dona Maria Borges, 68 anos, relata que a vida no Castelo já foi muito ruim, que quando chegaram para habitar o local não existia nada. Eles tiveram que trazer da Praia do Picanço, em suas canoas, as madeiras que eram construídas as suas residências. Ela diz que vieram primeiro as mulheres com as crianças enquanto que os homens ficaram na praia tentando retirar os $\operatorname{cavacos}^{7} \mathrm{e}$ os assoalhos das casas para construir suas novas residências no local. Segundo dona Maria, as dificuldades eram imensas com a inundação, mas o que os levou a sair realmente da praia foi à falta de água.

Tais histórias nos conduzem a mergulhar a esse universo, nos projetando ao momento em que ocorreu o fato narrado pelos moradores. Estas narrativas trazidas pelos moradores/pescadores vão ganhando sentido em relação a um grupo do qual o sujeito que narra está inserido. Percebemos ainda que quando os moradores começam a contar as histórias vividas por eles, os filhos e netos se aproximam para ouvir e compartilhar conosco aquelas lembranças.

Durante a realização deste estudo, as narrativas foram ouvidas cuidadosamente, assim como foram feitas anotações da movimentação que aconteciam nos espaços de conversa, percebendo através delas que as memórias individuais se ligam ativamente à memória

\footnotetext{
${ }^{6}$ Anotação de campo em: 20 de abril.2015

${ }^{7}$ Pequenos pedaços de madeira que eram usados como telhas em algumas palafitas na Amazônia.
} 
coletiva e social, passando pelo imaginário, e a imaginação de todos os presentes (HALBWACHS, 1990). É válido ressaltar que durante as conversas com os moradores perguntamos sobre a existência de fotografias do período em que residiram na Praia do Picanço, mas eles relataram que acabaram sendo perdidas ao longo do tempo e com a mudança, ficando apenas na memória e no imaginário dos moradores as imagens de tudo que viveram.

De acordo com Janaína Amado (1997, p. 135), as narrativas, mediadas pela memória, permitem que os informantes reelaborem suas vivências individuais e coletivas. Sendo que, ao utilizar a memória como instrumento na tentativa de entender um determinado grupo, nos deparamos com diversas sensações transmitidas pelas pessoas, que disponibilizaram um tempo para reviver momentos que se encontram em suas lembranças e trazendo expressões que remetem a conquistas, perdas, tristezas e emoções. É um momento de encontro entre o passado e o presente. Novaes (2008) considera que as:

Palavras por sua vez significam imagens mentais impressas na mente em função da nossa experiência com objetos. Uma palavra é a imagem de uma ideia e uma ideia é a imagem de uma coisa, como numa cadeia de representações. Palavras podem ser mais reais do que a própria coisa à qual elas se referem, por exemplo, quando a cena que descrevemos tem mais impacto do que a situação em si que vivenciamos. (NOVAES, 2008, p. 459)

Sendo que o uso de imagens se torna um instrumento primordial para auxiliar na tentativa de entendimento de um povo, comunidade, cultura e diversas leituras de mundo. Etienne Samain (1995, p. 26) colabora ao afirmar sobre a importância desse instrumento visual de pesquisa:

As funcionalidades lógicas que esses meios e instrumentos de comunicação (fala, escrita, visualidades modernas) proporcionam-nos deveriam tornar, ao contrário, mais humildes e solidários para ousar empreender uma reavaliação comum das nossas "tecnologias do intelecto". No que nos diz respeito (antropologia visual), conviria perguntar novamente o que se espera das imagens em antropologia ou, mais precisamente, a que destinos entendemos dever conduzi-las, como, e em vista de que as invocamos, pretendemos utilizá-las e delas tirar proveito, antropologicamente falando. (ETIENNE SAMAIN, 1995, p. 26)

As imagens construídas pelas narrativas dos moradores que acompanhamos nos permite visualizar questões vivenciadas pelas pessoas que residiram na extinta praia do Picanço e seguiram sua transição para a atual Vila do Castelo. Como apresentado anteriormente, esta encontra-se de frente para o Rio Caeté-Taperaçú e as principais referências em prédios são: a escola, a Igreja e o centro comunitário. Ao longo dos momentos de conversas com os moradores, essas principais referências prediais são elementos que 
auxiliam na reorganização das memórias em relação aos espaços e ações que fizeram e fazem parte do cotidiano dos moradores, ao citar, por exemplo, que a escola foi construída próxima à mangueira que as mulheres ficavam aguardando os maridos chegarem com os materiais para fazerem as suas casas.

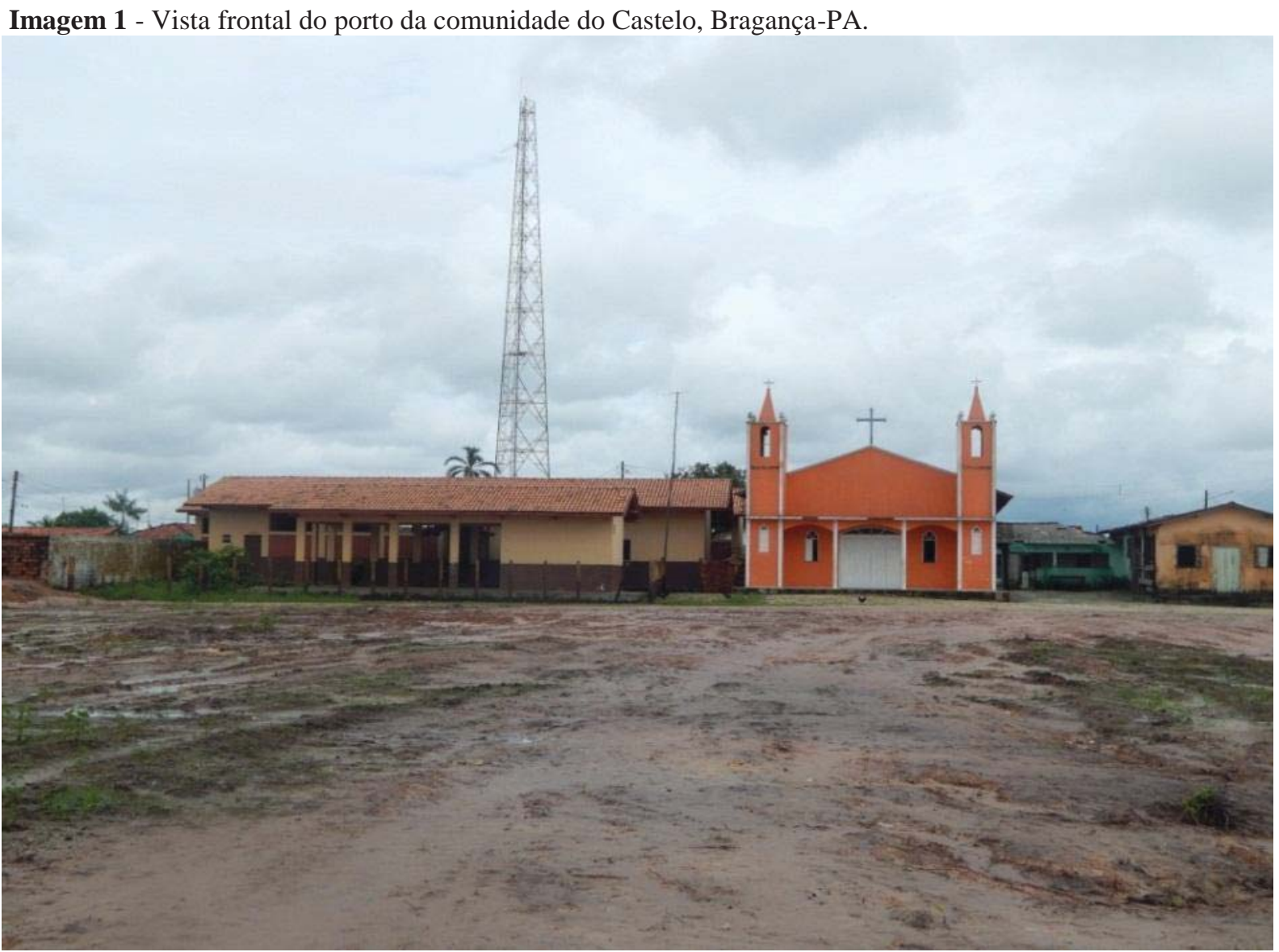

Fonte: Maria Adriana Leite, 2015.

A representação trazida nas memórias dos sujeitos ajuda a reconstruir um imaginário sobre a localidade, "a imagem tem esse poder de representar a realidade ausente ou distante, aquela que não estar presente aos nossos sentidos" (NOVAES, 2008). Como na imagem descrita pelo morador sobre a construção da escola, que se comparada a uma fotografia mais recente não encontraremos mais a mangueira descrita no relato, mas a partir da narrativa ficamos sabendo de sua existência, e também que suas sombras abrigaram as mulheres que esperavam por seus maridos durante o processo de mudança.

A imagem é considerada como um elemento histórico, mais precisamente como fonte, em que se pode fazer observações e diversas leituras sobre elas. Sendo importante verificar em que momento histórico foi tirado, quem a registrou e o que se projeta sobre ela. "O sentido 
de uma imagem depende daquelas que a precedem, e sua sucessão cria uma realidade nova, que não é a simples soma dos elementos empregados" (NOVAES, 2008 apud MERLEAUPONTY, 1983, p. 111).

Novaes (2008) destaca que a dualidade imagem/palavra, associada à construção natureza/cultura começou a ser melhor entendida e aceita academicamente a partir de pesquisas relacionadas à importância da memória nas sociedades sem escrita. Em 2007, durante atividade de intervenção realizada na escola Maria Augusta, com um grupo de movimento social da cidade de Bragança-PA, foi realizado o registro a seguir (imagem 2), que corresponde a visão privilegiada do refeitório da escola em direção ao rio, de frente para a maré. Voltando na comunidade para a realização da presente pesquisa não podemos mais apreciar o mesmo cenário, pois o poder público construiu o cais à beira do Rio, para uma possível proteção das margens da comunidade e também para atrelar os barcos ao chegarem do mar.

Imagem 2 - Registro da frente da comunidade realizado do refeitório da escola.

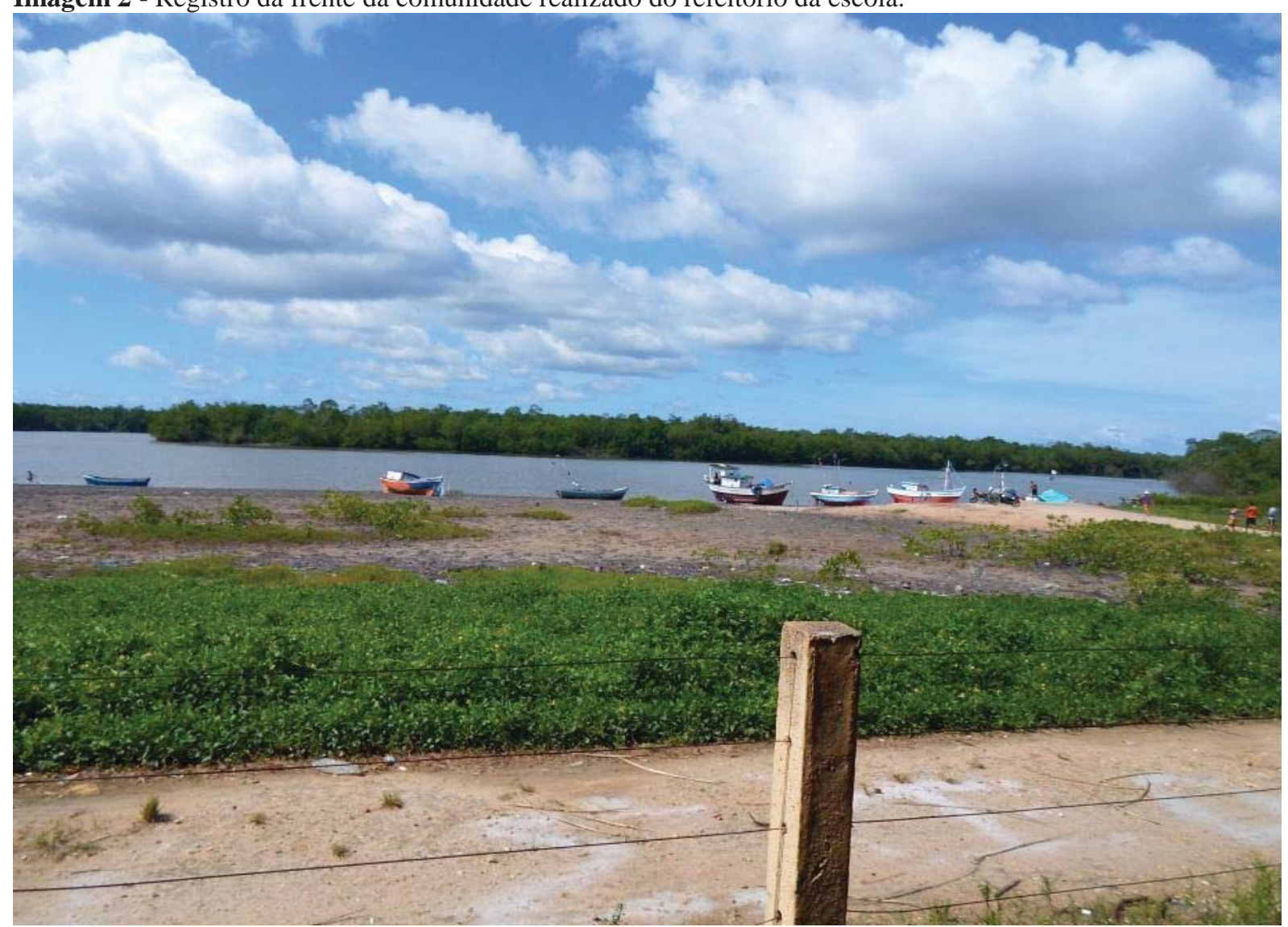

Fonte: Maria Adriana Leite, 2007.

Molina (2006, p. 29) relata sobre a importância das inter-relações sociais entre povos e seus territórios, afirmando que as relações são construídas para transformar os territórios, considerando: educação, cultura, produção, trabalho, infraestrutura, organização política, 
mercado, etc., como relações sociais constituintes das dimensões territoriais. Portanto, as mudanças são características constantes na história dos seres humanos. Vivemos em uma sociedade dinâmica, caracterizada por uma multiplicidade cultural, ideológica e social.

Em visita ao Castelo, em abril de 2015 durante a efetivação do presente trabalho, já conseguimos observar uma movimentação diferenciada, relacionada aos anos anteriores às margens do rio, em frente à escola. O processo de assoreamento e as mudanças naturais e sociais são perceptíveis durante as observações, sendo que as diferenças não dizem respeito apenas à estrutura dessa margem, mas também à dinâmica e movimentação dos sujeitos que ali frequentam.

Imagem 3 - Cais construído na frente da Comunidade. Registro de frente da escola.

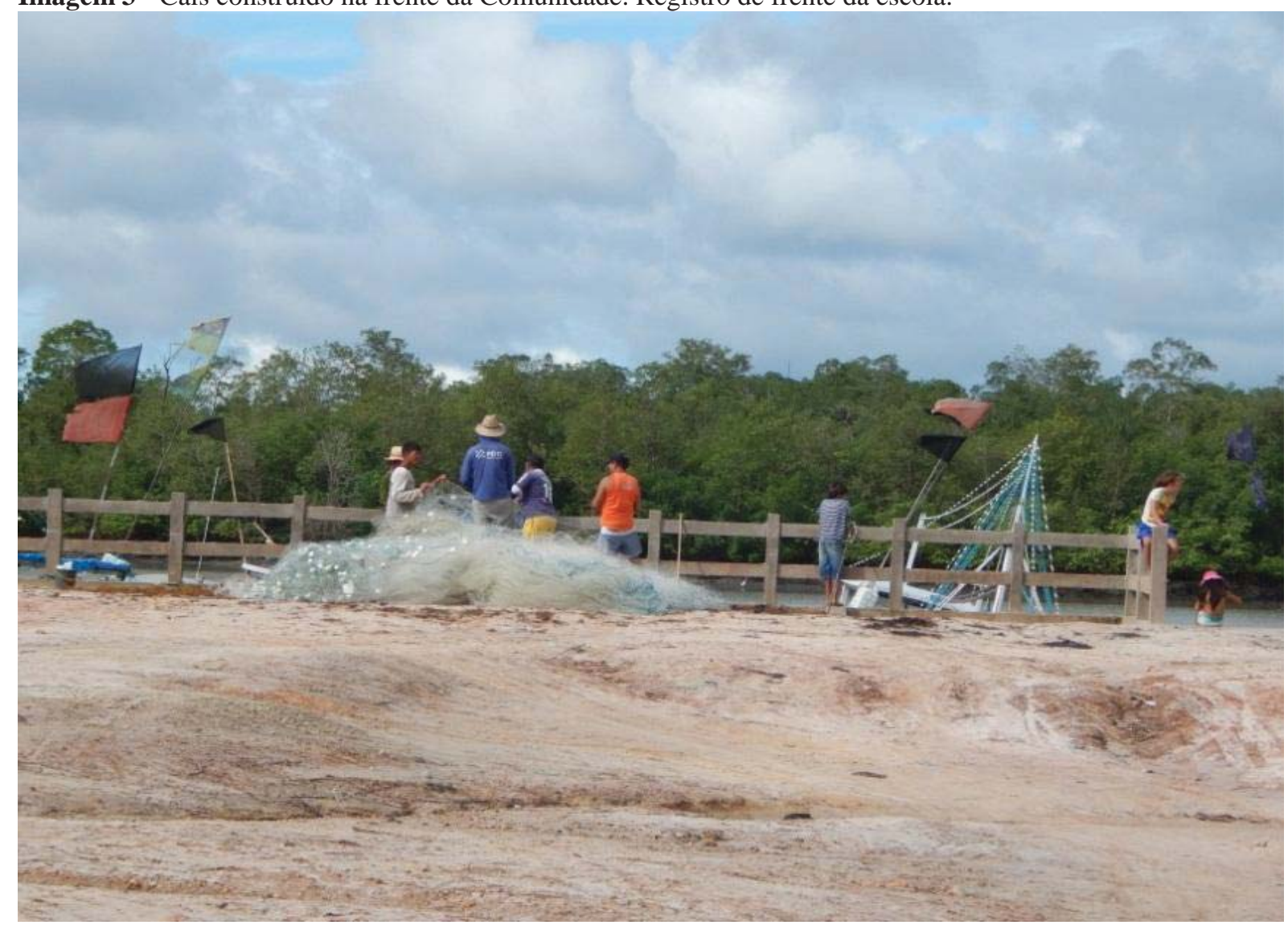

Fonte: Maria Adriana Leite, 2015.

A construção do cais de arrimo foi uma demanda solicitada pela comunidade junto ao poder público municipal, a qual solicitou à prefeitura a construção de uma proteção à beira do rio, para diminuir o assoreamento de suas margens e também para atracar as embarcações. Segundo alguns pescadores tal solicitação durou anos para ser atendida, sendo contemplados com a construção em novembro de 2014, porém em março de 2015 a construção foi embargada pela Secretaria de Meio Ambiente. Diante disso, a comunidade aguarda a liberação do processo. 


\section{A CULTURA DA PESCA NA COMUNIDADE DO CASTELO.}

A maioria das comunidades tradicionais pesqueiras vem sendo alvo de estudos no Brasil e, de acordo com Diegues (1999), essas iniciativas apontam para a construção de um campo particular do conhecimento nas pesquisas cientificas, principalmente nas ciências sociais, estudos que poderiam ser intitulados de Sócio-Antropologia Marítima (ou da Pesca).

A comunidade do Castelo possui sua economia voltada basicamente para captura de pescados, os pescadores normalmente são considerados pescadores de pequena escala (BERKES et al., 2006). Essa comunidade apresenta dependência dos recursos retirados, basicamente, da natureza, como a maré e o mangue que são os principais locais para a captura de peixes e mariscos. A cultura da pesca era praticada, inicialmente, com um caráter de subsistência. Posteriormente, o aumento da população que passou a habitar o local levou os moradores a criarem vias de acesso à parte urbanizada da cidade de Bragança-PA. Dessa forma, os moradores iniciaram a prática da pesca também para a comercialização, vendendo seus pescados para moradores da cidade e para empresas próximas. Entretanto, a dificuldade apresentada mais recorrente em relação à pesca artesanal, consiste na manutenção das estruturas das colônias de pescadores, devido à concorrência existente de forma desleal da pesca industrial.

Tradicionalmente a comunidade do Castelo possui características que lhe conferem um grande potencial para atividades econômicas voltadas à extração de caranguejos e pescados, pois sua área de extensão é de aproximadamente 42,2 hectares. Vale ressaltar, ainda, que a importância da pesca para a comunidade perpassa os limites econômicos e culturais. Está ligada historicamente à formação social desse contexto, que se constitui da diversidade cultural entre os povos e das características peculiares de cada pessoa. Michel Maffesoli (2001) considera que:

A cultura pode ser identificada de forma precisa, seja por meio das grandes obras da cultura, no sentido restrito do termo, teatro, literatura, música, ou, no senti do amplo, antropológico, os fatos da vida cotidiana, as formas de organização de uma sociedade, os costumes, as maneiras de vestir-se, de produzir, etc. (MAFFESOLI, 2001. p. 75)

Todas as famílias pesquisadas apresentam algum tipo de relação que envolve a atividade pesqueira, seja na sua captura, comercialização ou construindo e consertando os apetrechos e instrumentos a serem utilizados na pesca, sendo que, a prática cultural dessa atividade os 
transformam em sujeitos que se vestem com suas identidades e se sentem orgulhosos por fazerem parte desse universo.

Trabalhos desenvolvidos por Diegues (1973, p. 364), com a antropologia econômica em comunidades de pescadores no litoral brasileiro, revelam que "as relações conflituosas entre a pesca artesanal e a pesca empresarial em termos de modo de produção, enfocando os aspectos sócio-políticos da emergência das empresas pesqueiras no país". A comunidade do Castelo também passa por esses conflitos, envolvendo a pesca artesanal e a industrial. Muitos dos pescadores que trabalhavam em suas pequenas embarcações passam a trabalhar como empregados para as empresas de médio e grande porte no mercado bragantino. Ramalho (2004) afirma que:

\begin{abstract}
A Arte dos pescadores resulta de sua criatividade, de seu sentimento de liberdade e resistência, pois a pesca artesanal sempre se caracterizou, para seus profissionais, como uma não subordinação à sociedade canavieira e nem a sociedade urbana de consumo, que fizeram com que seu trabalho e seu modo de vida (para eles livres) permitissem o surgimento de uma arte (a arte da pesca) repleta de códigos próprios. (RAMALHO, 2004, p. 3)
\end{abstract}

É comum encontrar homens pescadores em frente às suas casas, construindo redes de pescar ou restaurando-as. O tempo estimado para a confecção de uma rede de pesca de tamanho grande $(1000 \mathrm{~m})$, de acordo com o relato de um pescador, é de aproximadamente três meses, desde que a pessoa se proponha a tecer todos os dias e tenha habilidade. Após tecida, coloca-se em volta da rede uma corda, onde são colocados pequenos pedaços de chumbos - o espaço entre eles é determinado pelo uso a ser feito da rede, em outras palavras, para qual tipo de pescaria ela se destinará. Os pesadores/artesãos do Castelo normalmente produzem suas redes para serem usados em benefício de suas famílias, mas é possível encontrar indivíduos que produzem para venda, desde que seja avisada previamente a encomenda. 
Imagem 6 e 7 - Pescadores restaurando a rede de pescar.
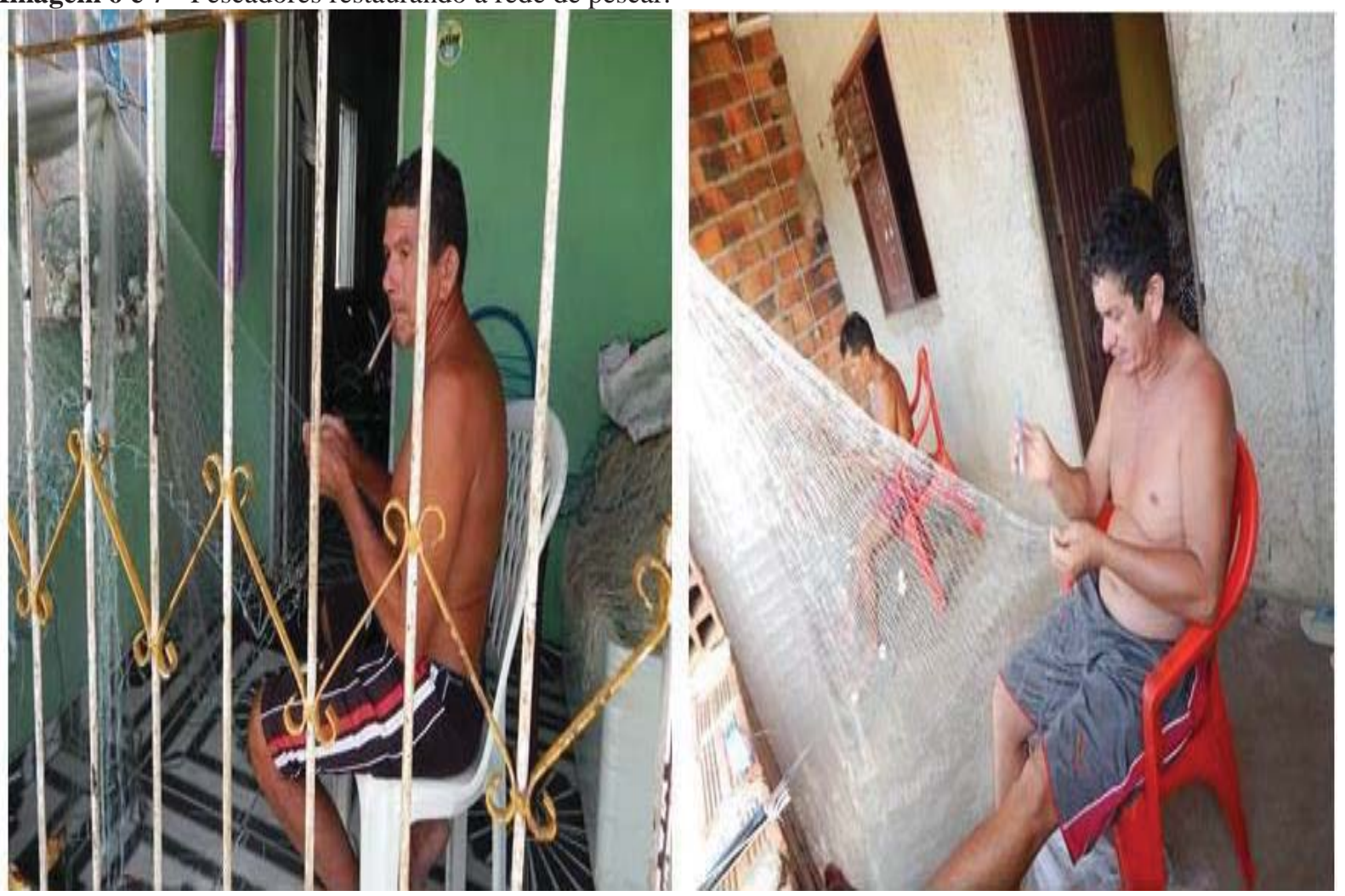

Fonte: Maria Adriana Leite, 2015.

Durante a realização da pesquisa foi necessário conversar com os moradores e também com algumas representatividades do local, dentre elas, a primeira moradora da comunidade, Dona Adelina, e o líder comunitário, o senhor Nelson. Este já foi presidente da reserva extrativista ASSUREMACATA (Ressex) e seu prestigio diante da comunidade se dá pelo fato de articular benefícios locais, como poço artesiano comunitário, levar as demandas para a construção de casas, nos programas federais voltados para os pescadores, e os representar em alguns momentos na colônia dos pescadores.

\section{HÁbITOS E PRÁTICAS DO DIA A DIA DE PESCADORES DA COMUNIDADE DO CASTELO.}

No universo das comunidades tradicionais da Amazônia brasileira é comum encontrarmos comunidades de pescadores que se caracterizam pelo domínio dos meios de produção e principalmente pela utilização da força de trabalho familiar na produção voltada à satisfação das necessidades familiares. Na comunidade do Castelo essa característica torna-se marcante, pois os meios de produção da comunidade estão voltados principalmente para o trabalho coletivo entre familiares. 
O Seu Zecão, 65 anos, pescador aposentado, conta que as atividades de pesca são constantes dentro da comunidade, afirmando que todos os dias seus filhos ou parentes chegam com vários peixes na beira do porto, ou na beira cais de arrimo. Ele revela ainda que "antes eram bem melhor, porque não tinha tanta gente comprando os peixes na beira da maré e a gente não precisava pescar todo dia”. Continuou dizendo que vem gente de toda a parte comprar peixe na beira do Rio ao fim da tarde, e quem chega atrasado não compra nada, porque o atravessador ${ }^{8}$ compra os peixes que os pescadores estão trazendo do mar e estes peixes são vendidos, na comunidade de Bacuriteua ou são levados à cidade de Bragança.

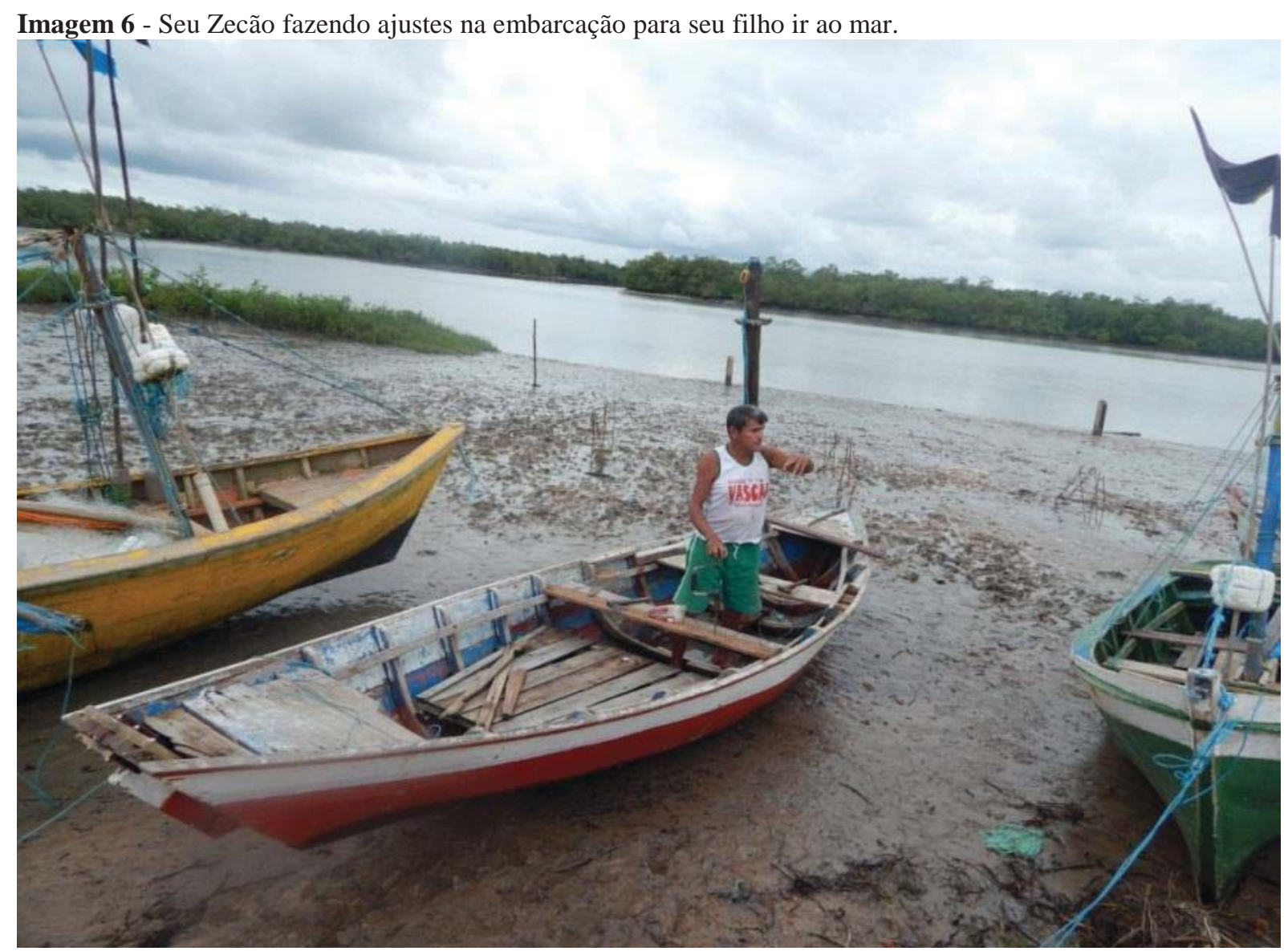

Fonte: Maria Adriana Leite, 2015.

Alguns pescadores dizem que é importante comercializar parte do que eles capturam durante as pescarias, para poder comprar produtos que não são originados da pesca, como por exemplo: componentes da cesta básica, roupas, eletrodomésticos, além de realizarem pagamentos de água, luz e gás.

\footnotetext{
${ }^{8}$ Pessoal que compra diretamente dos pescadores os animais capturados por um preço menor, para comercializar com os comerciantes em outras comunidades e/ou na cidade.
} 
O pescador Daniel, 28 anos, é bem enfático quando diz que "se a gente pescar a gente tem dinheiro". E comenta que muitos dos pescadores mais novos ou assumem os barcos dos seus pais e se associam à colônia dos pescadores ou tentam pescar para as empresas da região, chegando a passar de 15 a 30 dias em alto mar e apenas 10 dias em terra. As principais espécies de peixes que eles capturam nas embarcações das empresas são Cynoscion acoupa e Lutjanus campechanus, popularmente conhecidos na região como pescada amarela e pargo, respectivamente.

Imagem 8 - Daniel e Sérgio limpando a rede de pesca.

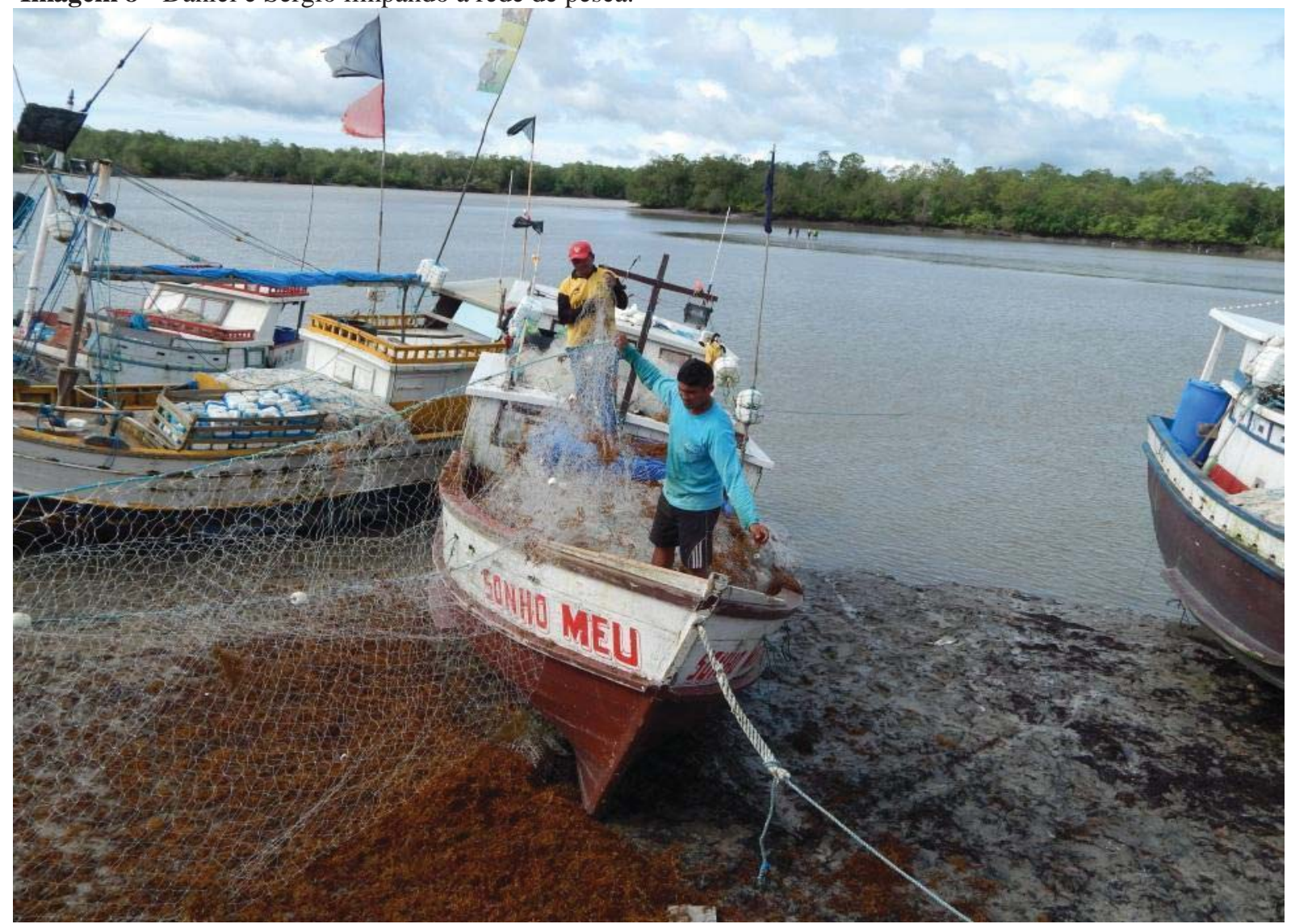

Fonte: Maria Adriana Leite, 2015.

Nesse cotidiano rico em vivências e atividades, as crianças também possuem o seu papel na atividade da pesca, pois absorvem saberes de seus pais, seguindo a hierarquia patriarcal na comunidade. Essas crianças manifestam seus aprendizados e saberes através das suas falas, brincadeiras, suas construções, seus desenhos e de seus registros escolares que ficam expostos na escola. Perceber que existem diferentes sujeitos sociais, evidencia-se como primeiro passo para a valorização das histórias de cada um, suas crenças, modo de viver e agir coletivamente. 


\section{CONSIDERAÇÕES FINAIS}

Este trabalho teve como ponto de partida a descrição da origem e características da comunidade do Castelo. A história da comunidade reporta um modo de vida peculiar, relacionado à conservação de elementos culturais e hábitos do cotidiano de comunidades tradicionais, os quais são adquiridos e ensinados de pais para os filhos, utilizando como principal recurso o extrativismo próximo à área da comunidade.

Todos os relatos sobre a origem da comunidade do Castelo estão de acordo com o trabalho de Feitosa (2012). Contudo, somente no presente estudo foi abordado também a cultura da pesca na comunidade do Castelo. Portanto, fornece-se novos relatos, imagens, experiências e características dessa localidade que se somam aos relatos que marcam uma sequência histórica social de ocupação e expansão da vila, agregada às práticas da atividade pesqueira. Observou-se, também, que a comunidade do Castelo apresenta a fonte de subsistência atrelada às riquezas da biodiversidade natural na região bragantina. No que diz respeito ao acervo de narrativas orais investigado, existe implicitamente uma tendência em aceitar que os depoimentos coletados possam constituir-se como fragmentos da história da comunidade, e que uma vez reunidos, constituirão a história e a identidade dos moradores do lugar.

O processo de formação territorial dessa comunidade está diretamente associado às atividades pesqueiras desenvolvidas pelos sujeitos. Sendo que, durante as conversas com os moradores (as), percebemos a subjetividade e a sensibilidade trazidas por cada um, favorecendo a sintetização das imagens construídas e que registram um tempo passado. Logo, estudos dessa natureza são imprescindíveis para registrar e catalogar a imensa diversidade de paisagens, imagens, informações e histórias de comunidades, como a Vila do Castelo.

\section{REFERÊNCIAS}

AMADO, Janaína. O grande mentiroso: tradição, veracidade e imaginação em história oral. In: Projeto História: Ética e História Oral. Revista do Programa de Estudos-PósGraduados em História e do Departamento de História/PUC/SP. São Paulo. nº 15, p. 1251361997.

BERKES, F. et al. Gestão de pesca de pequena escala: diretrizes e métodos alternativos. Rio Grande: Editora FURG, 2006.

BRASIL. Plano de Manejo da Reserva Extrativista Marinha de Caeté-Taperaçu (PA). Volume 2. Brasília: 2012. Disponível em: 
$<$ http://www.cidades.ibge.gov.br/xtras/temas.php?lang=\&codmun=150170\&idtema=67\&sear ch=para|braganca|censo-demografico-2010:-resultados-do-universo-caracteristicas-dapopulacao-e-dos-domicilios->. Acesso em: 13 mar. 2015.

BRASIL. Lei n. 4.771, de 15 de setembro de 1965. Institui o novo Código Florestal. Presidência da República, Casa Civil, Brasília, DF, 15 set. 1965. Disponível em: <http://licenciamento.cetesb.sp.gov.br/legislacao/federal/constituicao/constituicao_cap_6.pdf >. Acesso em: 5 de abril 2015.

DIEGUES, A. C. S. Populações Tradicionais em Unidades de Conservação: o Mito Moderno da Natureza Intocada. São Paulo: NUPAUB-USP, 1993.

A Sócio-Antropologia das comunidades de pescadores marítimos no Brasil. Etnográfica. v. 3, n. 2, p. 361-375, 1999. Disponível em: <http://ceas.iscte.pt/etnografica/docs/vol_03/N2/Vol_iii_N2_361-376.pdf11>. Acesso em: 22 jun. 2016.

FEITOSA. R. S. Morar, pescar e cuidar: Histórias de pescadores da RESEX Caeté-Taperaçú, Bragança-Pará, por meio de fundamentos teórico-metodológicos da História e da Antropologia. In: Encontro nacional de história oral, 11., 2012, Rio de Janeiro, Anais... Rio de Janeiro, 2012.

GARVÃO, R. F.; BAHIA, M. L.; TOURINHO, H. L. Z. Plano Diretor e Pesca Artesanal em Bragança: uma análise sobre a efetividade das diretrizes na atividade local. Revista Vitas: visões transdisciplinares sobre ambiente e sociedade, v. 5, p. 1-15, 2015.

GURAN. M. Considerações sobre a constituição e a utilização de um corpus fotográfico na pesquisa antropológica. Discursos Fotográficos. Londrina, v.7, n.10, p.77-106, jan./jun. 2011. Disponível em:

<http://www.uel.br/revistas/uel/index.php/discursosfotograficos/article/viewFile/9215/7841>. Acesso em: 15 ago. 2015.

HALBWACHS, Maurice. A memória coletiva. Tradução de Beatriz Sidou. São Paulo: Centauro, 2006.

MACHADO, Arlindo. Ilusão especular. São Paulo. Ed. Brasiliense, 1984.

MAFFESOLI, Michel. O imaginário é uma realidade. Revista FAMECOS. Porto Alegre, n. 15, agosto 2001. Disponível em:

<http://revistaseletronicas.pucrs.br/ojs/index.php/revistafamecos/article/viewFile/3123/2395>. Acesso em: 25 abril 2015.

MOLINA, Mônica Castagna. Educação do Campo e Pesquisa: questões para reflexão. In: BRASIL. Ministério do Desenvolvimento. Brasília: Ministério do Desenvolvimento Agrário, 2006.

RAMALHO. C. W. N. A arte de fazer-se pescador artesanal. In: Encontro Associação Nacional de Pós-Graduação e Pesquisa em Ambiente e Sociedade, 2., 2004. Indaiatuba, São Paulo. Anais... São Paulo: 2004. Disponível em: <http://www.anppas.org.br/encontro_anual/encontro2/GT/GT08/cristiano_ramalho.pdf>. Acesso em: 20 abril 2016. 
ROCHA, A. L.C. Antropologia das formas sensíveis: entre o visível e o invisível, a floração de símbolos. Horizontes Antropológicos. Porto Alegre, ano 1, n. 2, p. 107-117, jul./set. 1995. Disponível em: < https://www.ufrgs.br/ppgas/ha/pdf/n2/HA-v1n2a08.pdf>. Acesso em: 23 nov. 2017.

SAMAIN, Etienne. "Ver" e "Dizer" na tradição etnográfica: Bronislaw Malinowski e a fotografia. Revista Horizontes Antropológicos, Porto Alegre, ano 1, n. 2, p. 23-60, jul./set. 1995.

SEVERI. C. A palavra emprestada ou como falam as imagens. Revista de antropologia. São Paulo, v. 52, n. 2, p. 459-506, jul./dez., 2009, Disponível em:

<http://www.revistas.usp.br/ra/article/view/27316>. Acesso em: 23 nov. 2017. 